\title{
HUBUNGAN PENGETAHUAN MELALUI IKLAN OBAT (MAAG) TERHADAP SIKAP PEMILIHAN OBAT UNTUK SWAMEDIKASI PENGOBATAN MAAG PADA MASYARAKAT DI DUSUN V DESA BINJAI BARU KECAMATAN TALAWI
}

\author{
Rini Andarwati \\ Jurusan Farmasi Poltekkes Kemenkes Medan
}

\begin{abstract}
Abstrak
Penderita penyakit maag di Dusun V Desa Binjai Baru cukup banyak.Data didapat dari tenaga kesehatan yang ada di daerah ini hampir separuh masyarakat yang berobat mengalami gangguan lambung dan pengobtan secara swamedikasi pilihan utama bagi masyarakat tersebut. Tujuan penelitian ini adalah untuk mengetahui hubungan pengetahuan melalui iklan obat maag terhadap sikap pemilihan obat untuk swamedikasi pada masyarakat di Dusun V Desa Binjai Baru Kecamatan Talawi. Jenis penelitian ini adalah penelitian survey seksional atau potong silang (Cross sectional) dengan cara pengambilan sampel purposive sampling. Populasi dalam penelitian ini adalah 409 orang dan jumlah responden 80 orang. Hasil penelitian menunjukan bahwa tingkat pengetahuan masyarakat di Dusun V Desa Binjai Baru Kecamatan Talawi tentang iklan obat maag termasuk dalam kategori cukup baik (68.75\%), sikap tentang pemilihan obat untuk swamedikasi terhadap iklan obat maag cukup baik $(68.75 \%)$, dan pada analisa regresi logistik dengan nilai $\mathrm{p}=0.001$, maka terdapat hubungan yang signifikan antara pengetahuan melalui iklan obat maag dengan sikap untuk swamedikasi pengobatan maag pada masyarakat di Dusun V Desa Binjai Baru Kecamatan Talawi. Disarankan kepada pihak periklanan sebaiknya memberikan informasi yang lengkap mengenai iklan obat agar iklan obat dapat bermanfaat bagi masyarakat dan tidak menyesatkan. Dan Industri farmasi untuk lebih jujur dan rasional dalam memperkenalkan produknya melalui iklan.
\end{abstract}

Kata Kunci : Iklan Obat Maag, Pengetahuan, Sikap Pemilhan Obat, Swamedikasi

\section{LATAR BELAKANG}

Pengobatan sendiri atau swamedikasi adalah kegiatan atau tindakan mengobati diri sendiri dengan obat tanpa resep secara tepat dan bertangung jawab (rasional). Beberapa faktor yang mempengaruhi dilakukannya tindakan swamedikasi, yaitu: kondisi ekonomi masyarakat,berkembangnya kesadaran akan pentingnya kesehatan pada masyarakat,kampanye swamedikasi yang rasional di masyarakat mendukung perkembangan farmasi komunitas, tersebarnya distribusi obat melalui Puskesmas dan warung obat desa, serta promosi obat bebas dan obat bebas terbatas yang gencar dari pihak produsen baik melalui media cetak maupun elektronik hingga ke pelosok desa (Djunarko dan Hendrawati, 2011).

Iklan obat memiliki kontribusi membujuk atau mengingatkan masyarakat dalam memilih suatu produk obat. Salah satu cara untuk merebut perhatian masyarakat bukan saja iklan sebagai sarana informasi tetapi juga sebagai sebuah hiburan, yaitu menimbulkan perasaan gembira bagi siapa pun yang melihatnya, sehingga konsumen tertarik untuk membeli. Dan iklan obat dimanfaatkan oleh industri farmasi sebagai alat atau media untuk memperkenalkan suatu produk obat kepada masyarakat agar dapat menggunakan atau mengkonsumsi produk tersebut. Namun dengan maraknya iklan obat maag yang ditayangkan, ternyata iklan obat maag dianggap para pakar kesehatan memberikan informasi yang menyesatkan kepada masyarakat. Pasalnya iklan obat maag dianggap berlebihan karena mengklaim dapat mencegah penyakit maag. Hal ini tentu saja tidak sesuai dengan kandungan antasida dalam obat maag yang hanya mampu mengurangi keluhan lambung.Oleh karena itu tidak benar iklan obat maag yang menganjurkan untukpencegahan Dalam penilitian ini mengambil wilayah Dusun V Desa Binjai Baru Kecamatan Talawi dikarenakan wilayah ini merupakan jauh dari sarana pelayanan kesehata, penderita penyakit maag di daerah ini tercatat cukup banyak dimana informasi yang saya peroleh dari tenaga kesehatan yang berada di wilayah ini hampir separuh masyarakat yang berobat mengalami gangguan lambung dan obat yang biasa diberikan adalah antasida dan cimetidin. Kemudian penjualan obat maag dari toko obat yang ada di wilayah ini minimum 2000 tablet dan sirup 35 botol per bulan. Hal ini disebabkan karena masyarakat di wilayah ini memiliki pola makan yang kurang sehat, suka makanan yang asam dan pedas, minum kopi, perokok dan mayoritas pekerjaannya adalah supir. Dimana kebiasaan dari supir selalu menunda-nunda waktu makan sebelum sampai tempat tujuan. Perumusan masalah dalam penelitian ini adalah "Apakah ada hubungan pengetahuan melaui Iklan Obat (Maag) Terhadap Sikap Pemilihan Obat Untuk 
Swamedikasi Pengobatan Maag Pada Masyarakat di Dusun V Desa Binjai Baru Kecamatan Talawi. Tujuan penelitian ini untuk mengetahui hubungan pengetahuan melalui iklan obat maag terhadap sikap untuk swamedikasi pengobatan maag pada masyarakat di Dusun V Desa Binjai Baru Kecamatan Talawi.

Jenis penelitian yang digunakan pada penelitian ini adalah penelitian potong silang (Cross sectional) dengan melihat hubungan variabel bebas (pengetahuan melalui iklan) dan variabel terikat (sikap swamedikasi pengobatan maag). Lokasi penelitian dilakukan di Dusun V Desa Binjai Baru. Populasi dalam penelitian ini adalah seluruh masyarakat yang terdaftar sebagai pemilih dalam pemilihan umum di Dusun V Desa Binjai Baru Kecamatan Talawi. Berdasarkan data yang diperoleh dari Kantor Kepala Desa Binjai Baru jumlah pemilih Dusun V adalah 409 orang. Teknik sampling yang digunakan pada penelitian ini adalah purposive sampling, dengan jumlah sampel 80 orang.

Kriteria Inklusi penelitian ini adalah individu yang bertempat tinggal di Dusun V Desa Binjai Baru Kecamatan Talawi, pernah melihat iklan obat maag di televisi dan pernah melakukan swamedikasi pembelian obat maag yang di iklankan di televisi. Sedangkan kriteria eksklusinya adalah iklan obat selain obat maag. Analisa data menggunakn program SPSS dengan uji regresi logistik dengan kriteria $\leq 75 \%$ jawaban benar sikap cukup baik dan $76-100 \%$ jawaban benar sikap baik dan.$\leq 75 \%$ jawaban benar pengetahuan cukup baik dan $76-100 \%$ jawaban benar pengetahuan baik.

\section{HASIL PENELITIAN}

Dari data yang diperoleh tentang karakteristik responden yang meliputi jenis kelamin,umur, pendidikan dan pekerjaan dapat dilihat pada tabel berikut:

Tabel 1 Distribusi Frekuensi Karakteristik Responden

\begin{tabular}{|c|c|c|}
\hline Karekteristik & $\begin{array}{l}\text { Jumlah } \\
\text { (orang) }\end{array}$ & $\begin{array}{c}\text { Persentase } \\
(\%)\end{array}$ \\
\hline \multicolumn{3}{|l|}{ Jenis Kelamin } \\
\hline - Laki-laki & 41 & 51,25 \\
\hline - Perempuan & 39 & 48,75 \\
\hline Total & 80 & 100,0 \\
\hline \multicolumn{3}{|l|}{ Umur } \\
\hline - $17-35$ Tahun & 54 & 67,50 \\
\hline - $\quad 36-55$ Tahun & 26 & 32,50 \\
\hline Total & 80 & 100,0 \\
\hline \multicolumn{3}{|l|}{ Pendidikan } \\
\hline - $\quad$ SD dan SLTP & 16 & 20,0 \\
\hline - $\quad$ SMA & 54 & 67,50 \\
\hline - $\quad \mathrm{D} 1, \mathrm{D} 3$ dan $\mathrm{S} 1$ & 10 & 12,50 \\
\hline Total & 80 & 100,0 \\
\hline \multicolumn{3}{|l|}{ Pekerjaan } \\
\hline - IRT & 11 & 13,75 \\
\hline - $\quad$ PNS & 7 & 8,75 \\
\hline - Swasta & 3 & 3,75 \\
\hline - Wiraswasta & 53 & 66,25 \\
\hline - Pelajar & 6 & 7,50 \\
\hline Total & 80 & 100,0 \\
\hline
\end{tabular}

Tabel 1 memperlihatkan bahwa dari 80 responden, berdasarkan jenis kelami 41 orang $(51,25 \%)$ adalah laki-laki paling banyak dari perempuan $(48,75 \%)$ adalah perempuan. Untuk Karakteristik umur 54 orang $(67,50 \%)$ antara 17-35 tahun paling banyak,. Untuk karakteristik pendidikan paling banyak SMA, 54 orang $(67,50 \%)$. Untuk karakteristik pekerjaan mayoritas responden bekerja di bidang wiraswasta yakni sebanyak 53 orang $(66,25 \%)$.

Tabel 2 Distribusi Frekuensi Gambaran Pengetahuan Responden Penelitian Tentang Iklan Obat Maag di Dusun V Desa Binjai Baru Kecamatan Talawi

\begin{tabular}{cccc}
\hline No & $\begin{array}{c}\text { Kategori } \\
\text { Pengetahuan }\end{array}$ & Frekuensi & Persentase \\
\hline 1 & Baik & 25 & $31,25 \%$ \\
2 & Cukup baik & 55 & $68,75 \%$ \\
\hline & Total & 80 & 100 \\
\hline
\end{tabular}

Tabel 2 memperlihatkan bahwa dari 80 responden, tingkat pengetahuan cukup baik paling besar yaitu 55 orang $(68,75 \%)$.

Tabel 3 Kategori Sikap Responden Penelitian Terhadap Sikap Pemilihan Obat Untuk Swamedikasi Oleh Iklan Obat Maag

\begin{tabular}{clcc}
\hline No & Kategori Sikap & Frekuensi & Persentase \\
\hline 1 & Baik & 25 & $31,25 \%$ \\
2 & Cukup baik & 55 & $68.75 \%$ \\
\hline \multicolumn{2}{r}{ Total } & 80 & 100 \\
\hline
\end{tabular}

Tabel 3 memperlihatkan bahwa dari 80 responden, mayoritas responden memiliki sikap yang cukup baik dalam pemilihan obat untuk swamedikasi terhadap iklan obat maag di Dusun V Desa Binjai Baru Kecamatan Talawi yakni sebanyak 55 orang (68.75\%).

Analisa bivariat antara pengetahuan dengan sikap didapat nilai $\mathrm{p}=0.001$, artinya, terdapat hubungan antara pengetahuan melalui iklan obat maag dengan sikap untuk swamedikasi pengobatan maag pada masyarakat.

\section{PEMBAHASAN}

Berdasarkan hasil distribusi frekuensi pengetahuan terhadap 80 responden, didapatkan lebih dari separuh masyarakat $(68,75 \%)$ memiliki pengetahuan cukup baik terhadap pengetahuan melalui iklan obat maag. Hasil ini di dapat karena tingkat pendidikan responden mayoritas adalah SMA dimana responden mampu untuk memahami suatu objek yang ada pada iklan obat maag dan mengingat kembali tentang suatu objek yang spesifik yang dilihatnya, serta mengaplikasikannya. Umur responden yang mayoritas tergolong dalam usia remaja dan dewasa yang dimana rasa ingin tahu yang cukup besar terhadap suatu objek yang dilihatnya. Dan hasil penelitian ini sesuai dengan pendapat Notoatmodjo (1997) yang menyatakan bahwa pengetahuan merupakan hasil dari "tahu" dan ini terjadi setelah melakukan pengamatan terhadap suatu objek 
tertentu. Pada umumnya sebagian masyarakat mengamati iklan obat maag, hal ini sangat wajar mengingat bahwa masyarakat gemar menonton televisi yang dimana pada tayangan televisi terdapat penayangan iklan obat maag, baik disengaja maupun tidak disengaja masyarakat pasti melihatnya ketika mereka sedang menonton televisi. Pengetahuan masyarakat tentang iklan obat maag merupakan hasil pengolahan informasi melalui panca indra dan akal budi masyarakat yang mengamati atau melihat iklan obat maag pada tayangan televisi.

Hasil pengolahan data yang di dapat dari 80 responden bahwa hampir separuh $(68,75 \%)$ masyarakat memiliki sikap cukup baik dalam pemilihan obat untuk swamedikasi terhadap pengetahuan melalui iklan obat maag.

Hasil ini di dapat karena tingkat pendidikan responden mayoritas adalah SMA, dan pekerjaannya mayoritas adalah wiraswasta yang dimana tingkat penghasilannya masih rendah, mereka akan mencari alternatif pengobatan yang murah dan efektif secara terapi. Dan iklan obat menawarkan obat yang demikian, hal ini yang mendorong responden menerima dan merespon informasi yang diberikan oleh iklan obat maag yang ditayangkan di televisi tersebut. Dan hasil penelitian ini sesuai dengan pendapat Notoatmodjo (1997) bahwa dalam penentuan sikap yang utuh pengetahuan memiliki peranan yang penting. Dari pengetahuan yang cukup baik terhadap iklan obat maag di dapat akan mempengaruhi sikap untuk pemilihan obat untuk swamedikasi terhadap iklan obat maag.

\section{KESIMPULAN}

Ada hubungan antara pengetahuan melalui iklan obat maag dengan sikap pemilihan obat untuk swamedikasi pada masyarakat di Dusun V Desa Binjai Baru Kecamatan Talawi.

\section{SARAN}

1. Diharapkan bagi masyarakat agar lebih cerdas dalam memilih obat yang di iklankan, dan jangan mudah terpengaruh dengan iklan obat yang hanya memperkenalkan suatu produk tanpa memberikan informasi obat yang jelas.

2. Diharapkan bagi pihak perikalanan sebaiknya memberikan informasi yang lengkap mengenai iklan obat agar iklan obat dapat bermanfaat bagi masyarakat dan tidak menyesatkan.

3. Diharapkan bagi industri farmasi untuk lebih jujur dan rasional dalam memperkenalkan produknya melalui iklan, agar penggunaan obat kepada masyarakat lebih rasional.

4. Bagi peneliti lain yang melakukan penelitian dengan topik yang sama sebaiknya melanjutkan ke variabel tindakan dan untuk tempat yang berbeda.

\section{DAFTAR PUSTAKA}

Abadi, R. 2010. Jangan Minum Sembarang Obat. Jakarta: Sunda Kelapa Pustaka.

Anonim, 2010. Permenkes RI No. 1787/Menkes/Per/XII/2010 tentang Iklan dan Publikasi Pelayanan kesehatan. Departemen Kesehatan RI. Jakarta.

http://www.biofarma.co.id/wpcontent/uploads/2014/11/Permenkes-tentangIKLAN.pdf $>$ [Diakses tanggal 28 mei 2015]

Aspuah, S. 2013. Kumpulan Kuisioner dan Instrumen Penelitian Kesehatan. Yogyakarta: Medical Book

Departemen Kesehatan RI, 2011. Profil kesehatan Indonesia 2011. http://www.depkes.go.id/resources/download/pusda tin/profil-kesehatan-indonesia/profil-kesehatanindonesia-2011.pdf $>$ [diakses tangal 3 Juni 2015].

Djunarko, I dan Hendrawati, Y. D., 2011. Swamedikasi yang Baik dan Benar. Yogyakarta: Citra Aji Parama.

Fitriani, S. 2011. Promosi Kesehatan 1. Yogyakarta: Graha Ilmu.

Katzung, B.G. 2001. Farmakologi Dasar dan Klinik.Jakarta: Salemba Medika.

Kusumadewi, Y dkk., 2011. Peranan Teknologi Informasi \& komunikasi di Bidang Obat dan Pengobatan dalam Mendukung Perlindungan Pasien. Yogyakarta: Graha Ilmu.

Notoatmodjo, S. 1997. Ilmu Kesehatan Masyarakat. Jakarta: Rineka Cipta.

Notoatmodjo, S. 2010. Metodologi Penelitian Kesehatan. Jakarta: Rineka Cipta.

Rachmawati, H. 2011. Pengaruh Iklan Obat Flu di Televisi Terhadap Pemilihan Obat Secara Swamedikasi Pada Masyarakat Malang.

http://fikes.umm.ac.id/files/file/Penelitian\%20Dosen/Hidaj ah\%20Rachmawati/Farmasains\%20Profil.pdf $>$ [Dia kses tanggal 25 Mei 2015].

Sugiyono. 2010. Metode Penelitian Kuantitatif, Kualitatif dan $R \& D$. Ed.X. PT. Alfabeta.Bandung. 